\title{
An IoT based Tele-Health WBAN Model for Elderly People - A Review
}

\author{
R.Vajubunnisa Begum*1, Dr.K.Dharmarajan ${ }^{2}$ \\ ${ }^{1}$ Associate Professor (Research scholar, VISTAS), Department of Electronics and Communication Science, \\ JBAS College for Women, Chennai, Tamil Nadu, India \\ E-mail:vaju6666@gmail.com \\ ${ }^{2}$ Associate Professor, Department of Information Technology, \\ Vels Institute of Science Technology and Advanced Studies (VISTAS), Chennai, Tamil Nadu, India.
}

\begin{abstract}
The Tele-Health WBAN (Wireless Body Area Network) Model for patients required more attention especially old age people's healthcare services in Low-cost Internet of Things (IoT) Devices. The advancements in telemedicine have increased drastically towards wearable sensor devices and mobile phone-based applications in the last few years. The study presents the integration of IoT and wearable sensor devices in the Tele - Health system developed for tracking heart patients among the elderly people and also to prevent them from stroke. In order to meet the demand for old age people healthcare services, it is very much essential to provide assistance in cardiac disease diagnosis and suggest medication in their home with comfortable environment. Hence, they can avoid frequent visit to hospitals and long stays.
\end{abstract}

Keywords - IoT; Telehealth; Wireless Body Area Network; WBAN; Wireless Standards.

\section{Introduction}

In recent years, the Internet of Things (IoT) technology of telemedicine applications has piqued the attention of business, academicians, and science scholars all over the world for elderly people with heart disease who are at risk of stroke due to elevated blood pressure, high cholesterol, or diabetes, the introduction of IoT technologies into a modern e-health system is important. The most frequent cause of stroke is a clot blocking an artery in the brain (thrombosis).

The blood and oxygen flow to the portion of the brain supplied by the clotted blood artery is then cut off. The cells in that region of the brain die as a result of the loss of blood and oxygen, and the part of the body it regulates ceases functioning. A cholesterol plaque forms when one of the brain's narrow blood vessels ruptures and the clotting process begins. The same risk factors that induce narrower blood vessels in the heart and heart attack also apply to narrowed blood vessels in the brain. Many that are elderly who have elevated blood pressure, high cholesterol, or diabetes are at risk for stroke.

In this paper, we present a study of Tele-Health Monitoring System. Wearable wireless medical devices can be connected to a patient in a body area network (BAN) or a wireless sensor network (WSN) to constantly track vital signs. The cloud computing system captures vital data in real time and saves it in a database. The key feature of cloud computing is that it helps medical personnel and users to access data in a structured manner. Data collection and assessment will be done by the cloud network, and reviews will be submitted to them in order to deliver treatment over the internet. WBAN was created with care systems and emergency conditions in mind. In such cases, the network's tiny iot devices gather critical information from the body and transfer it to the hospital's medical centre. This detail is then reviewed for diagnosis by a physician or a consultant in the hospital. Since, the WBAN uses functional contact, communication is reliable. WBAN is distinct from memory. WBAN's security protocols are distinct from those of WSNs. WBAN is really useful for traditional Wireless Sensor Networks (WSN) in that its sensors have reduced power and practitioners of medical line as well as for old aged patients.

\section{Literature Survey}

S.F. Khan [1], in this paper has presented a body sensors platform for bodily sensors which are linked straight with patient's smart phone to receive in sequence at run time. This information is processed and stored in the cloud storage. The stored information may also be accessed through practitioners and medical staff later on to observe and display sufferers' wellbeing. For the identification of device and information processing of equipment the RFID, WSN, etc are used. The information of a patient's health to the medical professionals via smart phones using loT.

Abawajy et al., in [2], implemented a patient health monitoring (PPHM) based on system integrated cloud computing and Internet of Things technologies, and applied in the real-time monitoring in order to prepare a case study of a patient suffering from congestive heart failure using ECG, showing flexible, energy-efficient, and scalable remote patient health status monitoring framework. In addition, it makes health data clustering and classification mechanism to enable good patient care. 
Erden et al., in [3], published a survey on signal analysis and processing techniques employed with different types of sensors, such as pyro-electric infrared, and vibration sensors, accelerometers cameras, depth sensors, and microphones, analysing the increase of diseases and healthcare costs, shortage of caregivers, and a rise in the number of individuals unable to live independently.

Cirani and Picone, in [4], analyzed the characteristics of wearable applications for IoT scenarios and describe the interaction patterns that should occur between wearable or mobile devices and smart objects, as well as presented an implementation of a wearable-based Web of Things application used to evaluate the described interaction patterns in a smart environment, deployed within their department's IoT testbed.

Pasluosta et al., in [5] carried out a detailed review and discuss the existing wearable devices and the Internet-ofThing's infrastructure used to Nervous system disorder, prioritizing how this technological tool may lead to a shift in paradigm in terms of diagnostics and treatment. Spanò, Pascoli, and Iannaccone, in [6] proposed an Electrocardiogram remote monitoring system dedicated to Long-term residential health monitoring integrated with Internet of Things.

Thapliyal, Khalus and Labrado, in [7], published a survey on Internet of Things and medical devices as alternative technologies to recognize stress and manage using cloud-based services, smart phone apps and wearable smart health devices to aggregate and compute large data sets that track stress behaviour over long periods of time. Rios and Bezerra, in [8], analysed that devices can be worn are also used to take care of elderly people. In this context, a system developed for vital signs monitoring on elderly people in old age homes.

Mr.Anand D.Acharya and Mrs.Shital N.Patil in [9], have presented a real-time framework to achieve active monitoring of patient's data like ECG, Temperature, BP, Pulse rate, and also controlling in the absence of doctor. A. Divya priya and Sundar in [10], developed and implemented a prototype which incorporates pulse rate sensor \& temperature and also inform the physician about the patient's condition continuously.

\section{Methodology}

Internet of Medical Things has become a common area in healthcare in recent years; it refers to the use of Android device devices, medical sensors, and cloud storage to track patient vitals, as well as the use of networking technology to transfer data to a cloud computing system. Practitioners should use data from WBAN layer in order to accurately observe, assess, and treat patients. Fig 1.Represents a condition in which the patient's health status and vital details are continuously gathered by attached body sensors. Data is then sent via gateway router / Bluetooth / Zigbee / Wi-Fi / 3G to personal assistant devices in connectivity layer, where it is evaluated and saved on a cloud storage network for later review. The captured sensor data would help the physician during an emergency condition in order to improve and enhance the patient's health in services layer.

The WBAN hardware platform is set up to connect with the physician over the Internet and a smartphone. It will encourage physicians to keep track of their patients' wellbeing from anywhere in the world. The sensors in this device capture the patient's physiological records, such as heart rhythm, blood pressure, and pulse rate. The patient is then closely watched by this device, with data being transmitted to the Internet and kept on a medical server.The physician and patient will track the patient data at any time from all over the world using the Home server IP address given. If the sensor value exceeds the threshold data, the patient receives an emergency warning. Thus, the patient's health criteria are carefully tracked, and daily reporting through the medical server to a physician would assist in having a correct diagnosis and providing emergency ambulance service for near-perfect treatment. The IoT data collection will assist the patient in recovery faster and will also allow for improved medical services to be offered to patients at a low cost. The cloud service also plays a major role in weather forecast and other related services

In the event of any anomalies, a warning will be issued to all medical providers and physicians, instructing them to take the appropriate measures to provide emergency assistance to the patient.

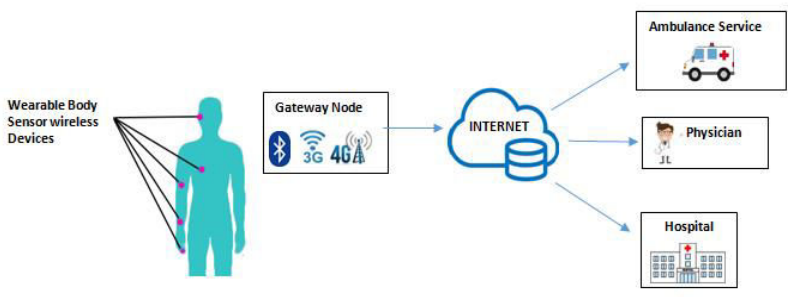

Fig. 1: Architecture of Patient monitoring system using Wireless Body Area Network

One more choice is also to build wireless body sensor networks-based on wearable devices. Patients are outfitted with handheld, miniaturised, and cellular devices capable of calculating, pre-processing, and wirelessly reporting different physiological, biochemical, and kinematic bio indications (e.g., ECG, EEG, EMG, Motion, Blood Glucose, body temperature, $\mathrm{SpO} 2$, blood pressure) to telehealth services in WBSN-enabled eHealth systems. This will provide for the appropriate customised, long-term, and 
real-time remote supervision of chronic patients, as well as integrated connectivity with the patient's medical record and collaboration with nursing and medical support. People in today's hectic world tend to keep track of their everyday tasks in order to better their life. Wearable devices worn as attachments on the body and use wearable applications for a number of functions. Wearables use IoT and cloud computing to offer a range of services. These devices can share data between themselves and the network due to the Internet of Things. Wearable gadgets and wearable applications are becoming more popular every day, from physical exercise to the fashion industry.

Table1. Comparison of Different Protocols

\begin{tabular}{|c|c|c|c|c|c|c|c|c|}
\hline \multirow{2}{*}{ Standard } & Coverage & $\begin{array}{c}\text { Data } \\
\text { Rates }\end{array}$ & Frequency & $\begin{array}{c}\text { Bandwidth } \\
\text { Requirements }\end{array}$ & $\begin{array}{c}\text { Power } \\
\text { Requirements }\end{array}$ & $\begin{array}{c}\text { Networking } \\
\text { Topology }\end{array}$ & Security & $\begin{array}{c}\text { Complexity } \\
\text { (Device/ } \\
\text { Application) }\end{array}$ \\
\hline Wi-Fi & $100 \mathrm{~m}$ & $\begin{array}{c}11 \text { and } \\
54 \mathrm{Mbps}\end{array}$ & $\begin{array}{c}2.4 \mathrm{GHz} \\
\text { and } 5 \mathrm{GHz}\end{array}$ & $20 \mathrm{MHz}$ & High & $\begin{array}{c}\text { Infrastructure } \\
\text { (point-hub) }\end{array}$ & $\begin{array}{c}\text { AES block cipher } \\
\text { and 32-bit CRC }\end{array}$ & High \\
\hline Bluetooth & $10 \mathrm{~m}$ & $1 \mathrm{Mbps}$ & $2.4 \mathrm{GHz}$ & $1 \mathrm{MHz}$ & Medium & $\begin{array}{c}\text { Ad hoc, very } \\
\text { small network }\end{array}$ & $\begin{array}{c}\text { 64- and 128- } \\
\text { bit encryption } \\
\text { and 16-bit CRC }\end{array}$ & High \\
\hline UWB & $10 \mathrm{~m}$ & $\begin{array}{c}100-500 \\
\mathrm{Mbps}\end{array}$ & $3.1-10.6 \mathrm{GHz}$ & $\$ 500 \mathrm{MHz}$ & Low & Point-to-point & $\begin{array}{c}\text { AES block cipher } \\
\text { and 16-bit CRC }\end{array}$ & Medium \\
\hline ZigBee & $70-100 \mathrm{~m}$ & $\begin{array}{c}250 \\
\mathrm{Kbps}\end{array}$ & $2.4 \mathrm{GHz}$ & $2 \mathrm{MHz}$ & Very low & $\begin{array}{c}\text { Ad hoc, peer- } \\
\text { to- peer, star or } \\
\text { mesh }\end{array}$ & $\begin{array}{c}\text { 128 AES with } \\
\text { application layer } \\
\text { security }\end{array}$ & Low \\
\hline $\begin{array}{c}\text { Wireless } \\
\text { USB }\end{array}$ & $10 \mathrm{~m}$ & $\begin{array}{c}480 \\
\mathrm{Mbps}\end{array}$ & $3.1-10.6 \mathrm{GHz}$ & $528 \mathrm{MHz}$ & Low & Point-to-point & AES 128 & Low \\
\hline IR wireless & $\begin{array}{c}<10 \mathrm{~m} \mathrm{with} \\
\text { LOS }\end{array}$ & $4 \mathrm{Mbps}$ & $16 \mathrm{KHz}$ & $2.54 \mathrm{MHz}$ & Low & Point-to-point & Very secure & Low \\
\hline
\end{tabular}

AES- advanced encryption standard; CRC- cyclic redundancy check; IR- infrared; UWB- Ultra Wideband; Kbps- kilobits per second; LOS, line of sight.

Table 2. Comparative Study of Research Works

\begin{tabular}{|c|c|c|c|c|c|c|}
\hline Reference & Objective & $\begin{array}{l}\text { Hardware } \\
\text { Platform }\end{array}$ & $\begin{array}{c}\text { Software } \\
\text { Tool }\end{array}$ & $\begin{array}{c}\text { Communication } \\
\text { Technology }\end{array}$ & $\begin{array}{c}\text { Results / } \\
\text { Contribution }\end{array}$ & Remarks \\
\hline $\begin{array}{c}\text { S.F.Khan } \\
{[1]}\end{array}$ & $\begin{array}{l}\text { Authors suggest a full } \\
\text { surveillance life cycle } \\
\text { and efficient } \\
\text { healthcare monitoring } \\
\text { system based on the } \\
\text { Internet of Things and } \\
\text { RFID tags. The } \\
\text { experimental findings } \\
\text { reported in this paper } \\
\text { illustrate the stable } \\
\text { performance in the } \\
\text { face of a number of } \\
\text { medical emergencies. }\end{array}$ & $\begin{array}{l}\text { Micro- } \\
\text { Controller } \\
\text { (ATmega } \\
32 \text { ) }\end{array}$ & $\begin{array}{c}\text { Android } \\
\text { Application }\end{array}$ & $\begin{array}{c}\text { Wi-Fi / RFID / } \\
\text { Bluetooth }\end{array}$ & $\begin{array}{l}\text { The association of the } \\
\text { WEAN with an } \\
\text { Android Smartphone } \\
\text { advances enormous } \\
\text { practicality. } \\
\text { Therefore, this } \\
\text { electronics healthcare } \\
\text { has the capability of } \\
\text { worldwide } \\
\text { acceptance. }\end{array}$ & $\begin{array}{l}\text { The RFID delivers } \\
\text { information that are } \\
\text { controlled by the } \\
\text { electromagnetic integrator. } \\
\text { Global system for mobile } \\
\text { communication (GSM) } \\
\text { device itself which is not } \\
\text { recommended by the } \\
\text { doctors since it may lead to } \\
\text { harm the patients due to } \\
\text { electromagnetic radiations. } \\
\text { No alert mechanism } \\
\text { provided. }\end{array}$ \\
\hline $\begin{array}{l}\text { A.Dhillon } \\
\text { et.al. } \\
\text { [11] }\end{array}$ & $\begin{array}{l}\text { Introduced an edge- } \\
\text { computing based } \\
\text { complex Event } \\
\text { Processing (CEP) } \\
\text { architecture for remote } \\
\text { patient monitoring. } \\
\text { The RPM techniques } \\
\text { use the mobile device } \\
\text { as an IoT gateway } \\
\text { agent where complex } \\
\text { events are detected }\end{array}$ & $\begin{array}{l}\text { Embedded } \\
\text { CEP } \\
\text { System on } \\
\text { Android } \\
\text { Phone. }\end{array}$ & $\begin{array}{c}\text { Mobile } \\
\text { CEP } \\
\text { application } \\
\text { s, J SON } \\
\text { Format }\end{array}$ & $\begin{array}{l}\text { Bluetooth / Wi- } \\
\text { Fi }\end{array}$ & $\begin{array}{c}\text { Work Load and system } \\
\text { parametric such as } \\
\text { CEP latency, arrival } \\
\text { time, queuing delay for } \\
\text { every complex event } \\
\text { generated per unit time } \\
\text { even analysed in terms } \\
\text { of graph where } \\
\text { performance metrics } \\
\text { used in different runs. }\end{array}$ & $\begin{array}{l}\text { Real Frame Performance } \\
\text { analysis is not significant } \\
\text { after the value of } 500 \text { event } \\
\text { / Second reached because } \\
\text { any further increase in time } \\
\text { of occurrence for a CE that } \\
\text { leads to increase in CEP } \\
\text { latency. System is scalable } \\
\text { for arrival times lower than } \\
2000 \text { events / Sec. }\end{array}$ \\
\hline
\end{tabular}




\begin{tabular}{|c|c|c|c|c|c|c|}
\hline $\begin{array}{l}\text { A. Divya } \\
\text { priya } \\
\& \\
\text { Sundar } \\
{[10]}\end{array}$ & $\begin{array}{l}\text { They have developed } \\
\text { and implemented a } \\
\text { prototype which } \\
\text { incorporates pulse rate } \\
\text { sensor \& temperature } \\
\text { and also inform the } \\
\text { doctor about the } \\
\text { patient's condition } \\
\text { continuously. }\end{array}$ & $\begin{array}{l}\text { Raspberry } \\
\text { Pi } \\
\text { BCM2837 } \\
\text { Quad-core } \\
\text { processor }\end{array}$ & $\begin{array}{l}\text { Web } \\
\text { Server. }\end{array}$ & $\begin{array}{l}\text { Bluetooth / } \\
\text { Wi-Fi }\end{array}$ & $\begin{array}{l}\text { The results of body } \\
\text { temperature and } \\
\text { heart rate in } \\
\text { numeric value were } \\
\text { updated and stored } \\
\text { in the database }\end{array}$ & $\begin{array}{l}\text { This system possess a } \\
\text { solution for only } 2 \\
\text { parameters of the ill } \\
\text { patients, the other } \\
\text { parameters were not } \\
\text { discussed. }\end{array}$ \\
\hline $\begin{array}{c}\text { Abawajy } \\
\text { et al } \\
{[2]}\end{array}$ & $\begin{array}{c}\text { Authors present a } \\
\text { pervasive patient } \\
\text { health } \\
\text { monitoring (PPHM) } \\
\text { System infrastructure. } \\
\text { PPHM is based on } \\
\text { integrated cloud } \\
\text { computing } \\
\text { and Internet of Things } \\
\text { Technologies. }\end{array}$ & $\begin{array}{c}\text { Physical } \\
\text { Machines } \\
\text { using } \\
\text { SMO } \\
\text { based } \\
\text { classificati } \\
\text { on } \\
\text { network, } \\
\text { Bayes Net } \\
\text { and } \\
\text { Classical } \\
\text { Naïve } \\
\text { Bayes } \\
\text { Algorithm. }\end{array}$ & $\begin{array}{l}\text { Personal } \\
\text { Server }\end{array}$ & Bluetooth & $\begin{array}{c}\text { Accuracy is } 98.9 \% \\
\text { with } 2 \text { clusters } \\
\text { achieved. } \\
\text { Performance } \\
\text { evaluation done. }\end{array}$ & $\begin{array}{l}\text { Privacy and security } \\
\text { aspects }\end{array}$ \\
\hline $\begin{array}{l}\text { Acharya } \\
\text { et. al. } \\
\text { [9] }\end{array}$ & $\begin{array}{l}\text { They have presented a } \\
\text { real-time framework } \\
\text { to achieve active } \\
\text { monitoring of patient's } \\
\text { data like ECG, } \\
\text { Temperature, BP, } \\
\text { Pulse rate, and also } \\
\text { controlling in the } \\
\text { absence of doctor. }\end{array}$ & $\begin{array}{l}\text { Arduino } \\
\text { UNO and } \\
\text { Raspberry } \\
\text { Pi }\end{array}$ & $\begin{array}{l}\text { Android } \\
\text { Application }\end{array}$ & Wi-Fi Module & $\begin{array}{l}\text { The output results } \\
\text { such as heart rate, } \\
\text { temperature, BP and } \\
\text { oxygen level for } 2 \\
\text { persons were } \\
\text { observed and results } \\
\text { compared with } \\
\text { standard value. }\end{array}$ & $\begin{array}{l}\text { The major drawback of the } \\
\text { system is that both } \\
\text { interfaces for data } \\
\text { visualisation developed. }\end{array}$ \\
\hline $\begin{array}{c}\text { Mithir } \\
\text { Kumar } \\
\text { Jena \& } \\
\text { Irshad } \\
\text { Ahmad } \\
\text { Ansaari } \\
\text { [12] }\end{array}$ & $\begin{array}{l}\text { They have presented } \\
\text { the usefulness of } \\
\text { wearable devices, its } \\
\text { type, evolution, } \\
\text { advancement current } \\
\text { in technologies and } \\
\text { applications in the } \\
\text { healthcare }\end{array}$ & $\begin{array}{l}\text { WBAN, } \\
\text { Wearable } \\
\text { devices. }\end{array}$ & $\begin{array}{l}\text { Cloud } \\
\text { Server, } \\
\text { Tele- } \\
\text { Medicine } \\
\text { server }\end{array}$ & $\begin{array}{l}\text { Various } \\
\text { communicatio } \\
\text { n protocols } \\
\text { according to } \\
\text { different } \\
\text { levels. }\end{array}$ & $\begin{array}{l}\text { Discussion carried } \\
\text { out in current } \\
\text { techniques with } \\
\text { regard to variety of } \\
\text { applications related } \\
\text { to the measurement } \\
\text { of biological signal. }\end{array}$ & $\begin{array}{l}\text { Limitation of current } \\
\text { techniques during the } \\
\text { regular use of wearable } \\
\text { medical devices faced by } \\
\text { consumers still exist. }\end{array}$ \\
\hline
\end{tabular}

\section{Applications of WBAN}

WBAN offers portability, freedom of movement, low power usage, safety for human exposure, tracking human physiological processes, higher security protection, decreased clinical errors, and more significant in real-time data transmission, WBAN has a wide range of applications in the medical, sporting, and military fields. Wellness management, tension monitoring, respiratory attacks, emergency response, asthma, deep brain stimulation, wearable drug distribution, and other telemedicine uses without BANs are currently being pursued.

WBAN's core capabilities are telemedicine and online patient care. Telemedicine refers to the use of computer technologies to diagnose and treat patients who are situated in a distant area. WBAN also enabled the distribution of some healthcare facilities to patients who live in remote areas.

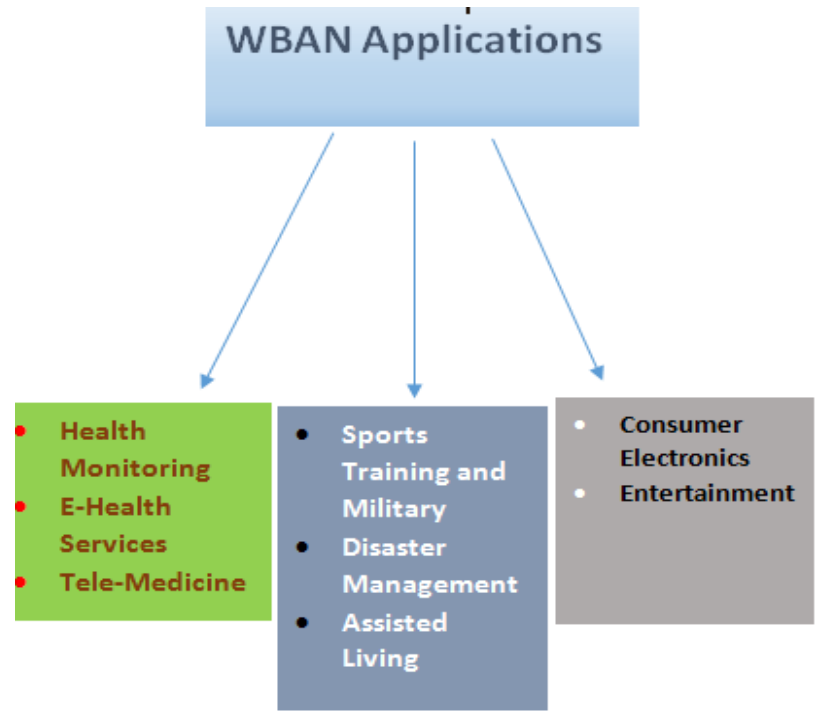

Fig. 2: WBAN Applications

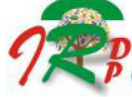


More and more patients will be served using telemedicine. Body sensors capture messages from the body and send them to doctors and physicians who are far away to interpret them. Doctors may use this data to estimate their patients' condition and make medical interventions and treatments. It will result in a more intelligent health-care environment. Patients' daily tasks should be tracked in order to extract vital parameters from the human body.

Patients can regain their natural physical ability by rehabilitative recovery techniques. An individual who has had a stroke will work independently with the right recovery measures and counselling. To ensure a proper motion pattern, these patients are continuously watched. Device consolidation, data transformation, authentic reviews, and residence healing wellness through devices that continuously track bodily functions are the key applications of WBAN in this field. This would enhance understanding of those biological processes.

This contributes to a higher quality of life. Elderly and older individuals will be tracked in their own homes thanks to elder care technology. The cost of healthcare will be reduced as a result of all this. The state of older people's health can be accurately measured with the help of these sensors and WBAN.

\section{IoT Challenges in WBAN Model}

The Internet of Things presents a new series of problems for healthcare firms and medical equipment manufacturers. Firms are designing technologies and devices that work with the Cloud in order to cut costs and increase efficiencies.

\subsection{Security}

- Encryption of cloud-connected medical devices Data protection in accordance with HIPAA and HITECH regulations.

- Patient data is exposed on smartphones via apps and in the cloud.

- Patient data is safely shared by trusted stakeholders.

- Low-power devices run hot and have a lower uptime when used with high load protection.

- Protection solutions for small medical devices have footprint limits.

- For massive data transfers, there could be bandwidth or network limits.

- Patients and suppliers can be harmed as a result of software or data breaches.

Interoperability - Data can flow freely through different technology standards such as Bluetooth and ZigBee. The WBAN framework should be modular as well, ensuring that network communication is not disrupted as the network grows.

Privacy - Users of the WBAN network are concerned that their personal details will be exposed. As a result, WBAN must ensure that personal information is kept private and safe.

System Hardware - The network's devices must be simple to use, lightweight, resource efficient, and energy efficient.

Sensor Validation - The information gathered by the sensors must be checked. This would aid in the detection of flaws in hardware and device designs. False readings will result in the end user receiving incorrect information.

Data Integrity - Data consistency should be preserved. Data is fragmented and transferred at different nodes in a cellular body area network. This can lead to data inconsistencies. As a result, information security must be ensured.

Interference - With a large-scale WBAN device installation, interference should be minimal. This would improve the sensor nodes' ability to coexist with other network equipment.

Information Management - WBAN generates a vast amount of data. Storing and handling too much data is a difficult but necessary challenge.

\section{Tele-health Applications}

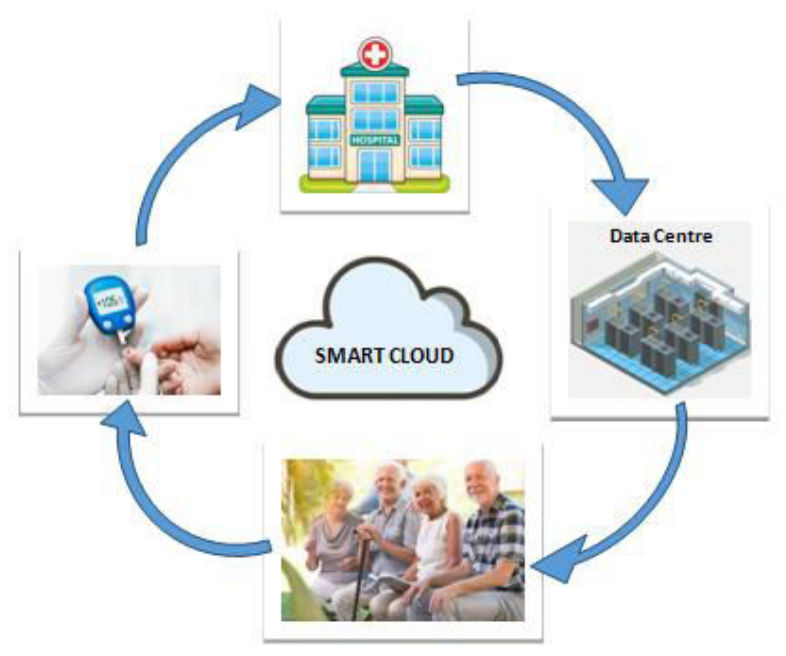

Fig. 3: Tele-Health Services for elderly patients

Body area networks provide a variety of features for end users as sensors like this are paired with wireless protocol like Wi-Fi, Bluetooth Low Energy, and ZigBee, as well as proprietary approaches. Figure 3 illustrates the 
different services offered to elderly patients. The same technologies, on the other hand, can be used to offer various facilities for people with particular illnesses or even health surveillance. Everyone is responsible for their own welfare, but the NHS has a role to play in aiding people in maintaining their health and well-being. To reduce health inequalities and ensure the NHS's long-term stability, the NHS's position in reducing bad health and encouraging healthier living is crucial.

Telehealth enables patients and doctors to interact through audio and video. It saves time and expense by sending the patient's medical history back to the doctor for consultation, but this method is not effective in an emergency. Wearable sensors are becoming more common every day, and they can help capture physiological data such as heart rate, pulse rate, and body temperature and transmit it to a consumer terminal (such as computers, smart phones, smart watches, as tablets, web portal, or, even, a specific embedded device).

Detection of suspicious cases in elderly suicidal individuals, as well as cancer detection (ability to detect nitric oxide from cancerous cells). This network will also assist disabled people who have eye implant chips inserted. WBAN also has benefits in cases such as

- Early attack, in which doctors will detect issues until the patient's condition deteriorates.

- Medication adherence, in which using WBAN will reduce the risk of illness and the need for cleaning procedures.

- Ease of patient transport, in which there would be no need to remove and re-join wires prior to moving a patient.

- When medical conditions require, a doctor would be able to easily incorporate or detach sensors for assessment of various vital signs.

\section{Conclusion}

In today's environment, remote human resources have become a vital need. The WBAN motivates us by allowing medicinal and non-medical apps to interact remotely with or without human intervention. Better health is now feasible due to data innovation. In light of embedded gadgets, it is appropriate that applications assist specialists' incomprehension inside a person. Patients and clinicians can interact with embedded sensors. We contrasted our solution to Wi-Fi, Bluetooth, ZigBee, IR wireless and other wireless technologies. In this article, we have reviewed a low-cost, discreet, low-power telehealth WBAN for healthcare diagnosis.

This article will serve as a source of inspiration for research career. Indicating with very low energy consumption has been developed by researchers. From a security standpoint, the actual rate of absorption is also calculated. Since WBAN consists of several sensors, the aim of our research is to reduce radiation-related health risks. Technologists or research scientists have been developing and refining the advanced research project based WBAN model.

\section{References}

[1] S.F. Khan, "Health care monitoring system in Internet of Thing (loT) by using RFID”. International Conference on IndustrialTechnology and Management, 2017.

[2] J.H. Abawajy, M. Mohammad and M. Hassan, "Federated Internet of Things and Cloud Computing Pervasive Patient Health Monitoring System'. IEEE Communications Magazine, vol. 55, pp. 48-53, 2017.

[3] F. Erden, S. Velipasalar, A.Z. Alkar and A.E. Cetin, "Sensors in Assisted Living: A survey of signal and image processing methods". IEEE Signal Processing Magazine, vol. 33, pp. 36-44, 2016.

[4] S. Cirani and M. Picone, "Wearable Computing for the Internet of Things”. IT Professional, vol. 17, pp. 35-41, 2015.

[5] C.F. Pasluosta, H. Gassner, J. Winkler, J. Klucken and B.M. Eskofier, "An Emerging Era in the Management of Parkinson's disease: Wearable Technologies and the Internet of Things". IEEEJournal of Biomedical and Health Informatics, vol. 19, pp. 1873-1881, 2015.

[6] E. Spanò, S.D. Pascoli and G. Iannaccone, "Low-Power Wearable ECG Monitoring System for Multiple-Patient Remote Monitoring”. IEEE Sensors Journal, vol. 16, pp. 5452-5462, 2016.

[7] H. Thapliyal, V. Khalus and C. Labrado, "Stress Detection and Management: A Survey of Wearable Smart Health Devices". IEEEConsumer Electronics Magazine, vol. 6, pp. 64-69, 2017.

[8] T.S. Rios and R.M.S. Bezerra, "WHMS4: An integrated model forhealth remote monitoring: A case study in nursing homes for theelderly." 10th Iberian Conference on Information Systems andTechnologies, 2015.

[9] Mr.Anand D.Acharya and Mrs.Shital N.Patil "IoT based Health Care Monitoring Kit". Proceedings of the Fourth International Conference on Computing Methodologies and Communication (ICCMC) IEEE Xplore Part Number:CFP20K25-ART; ISBN:978-17281-4889-2, 2020.

[10] A. Divya priya and Sundar"Health Monitoring System using IoT". International Conference on Vision towards Emerging Trends in Communication and Networking (ViTECoN), 2019

[11] A.Dhillon et.al. "MCEP : A Mobile Device Based complex Event processing system for Remote Healthcare", IEEE, 2018

[12] Mithir Kumar Jena and Irshad Ahmad Ansari " A Critical Review of Wireless Health Monitoring Devices". Conference on Information and Communication Technology (CICT), 2018.

[13] Rim Negra et. al. "Wireless Body Area Networks: Applications and technologies", Published by Elsevier B.V (The Second International Workshop on Recent Advances on Machine-to-Machine Communications), 2016.

[14] https://www.techsparks.co.in/thesis-in-wireless-body-area-network/ visited on 14 June 2021.

[15] https://www.ncbi.nlm.nih.gov/pmc/articles/PMC3719440/ visited on 14 June 2021 